\title{
Serum Lipase in Pulmonary Tuberculosis Patients in Kinshasa-A Hospital Based Study
}

\author{
M. K. Mbelu ${ }^{*}$, J. J. Malemba ${ }^{2}$, B. Kabengele², J. M. Kayembe'², D. N. Kayembe ${ }^{1}$ \\ ${ }^{1}$ Laboratory of Clinical Biology, Department of Medical Biology, University Hospital of Kinshasa, Kinshasa, \\ Democratic Republic of Congo \\ ${ }^{2}$ Department of Internal Medicine, University Hospital of Kinshasa, Kinshasa, Democratic Republic of Congo \\ Email: *mbelumamy@gmail.com
}

How to cite this paper: Mbelu, M.K., Malemba, J.J., Kabengele, B., Kayembe, J.M. and Kayembe, D.N. (2018) Serum Lipase in Pulmonary Tuberculosis Patients in Kinshasa-A Hospital Based Study. Journal of Tuberculosis Research, 6, 156-165.

https://doi.org/10.4236/jtr.2018.62015

Received: March 3, 2018

Accepted: June 19, 2018

Published: June 22, 2018

Copyright (C) 2018 by authors and Scientific Research Publishing Inc. This work is licensed under the Creative Commons Attribution International License (CC BY 4.0).

http://creativecommons.org/licenses/by/4.0/

\begin{abstract}
Context: The increase of serum lipase is established for pancreatic and bile duct disorders. However, the production of this enzyme by other organs, including the lungs, leads to the question of its potential role in the diagnosis of other conditions including lung diseases. Objective: The aim of the present study was to describe the profile of serum lipase in patients who suffered from the pulmonary tuberculosis and to identify its determinants. Patients and methods: A cross-sectional study was performed from July to October 2013 in four hospitals of Kinshasa (The University Hospital of Kinshasa, Lisanga medical Center and 2 medical centers of Save Army). Patients who suffered from tuberculosis were included. The levels of serum lipase, triglyceridemia, cholesterolemia, c-reactive protein were noted, as so as the hemogram profile and the prescribed treatment (category and phase). Results: One hundred and twenty-eight patients suffering from pulmonary tuberculosis were included. Forty three women (33.6\%) and 85 men (66.4\%). The sex ratio M/F was 1:9. Hyperlipasemia was observed in $44.5 \%$ of patients. The average level of serum lipase was $36.6 \pm 5.0 \mathrm{IU} / \mathrm{L}$ (normal value: $\leq 38 \mathrm{IU} / \mathrm{L}$ ) in tuberculosis patients and $30 \pm 2.3 \mathrm{IU} / \mathrm{L}$ in controls The lipid profile of the patients was normal. Conclusion: L Hyperlipasemia can be encountered, in varying proportions, during pulmonary tuberculosis. It would be an indication of inflammation of the pulmonary parenchyma.
\end{abstract}

\section{Keywords}

Pulmonary Tuberculosis, Serum Lipases, Kinshasa

\section{Introduction}

Lipases are defined as enzymes that hydrolyze glycerol esters of long chain of 
fatty acids. Only the ester bridged to carbons 1 and 3 (at positions $\alpha$ and $\alpha 1$ ) are attacked. The reaction products are two fatty acid molecules and one molecule of 2 -acylglycerol ( $\beta$-monoglyceride) per molecule of substrate [1] [2]. The properties of lipases have been widely exploited in the diagnosis and prognosis of pancreatic affections [1] [3] because the pancreas constitutes one of the sites of its synthesis. Indeed, the concentration of lipase in the blood increases in certain pathologies, in particular in case of inflammation of the pancreas, obstruction of the Wirsung canal, liver cirrhosis, hepatitis or even renal failure. On the other hand, a decrease in lipoprotein lipase (LPL) activity is observed in case of essential hypertriglyceridemia (Burger-Grutz's disease) and in case of hyperlipoproteinemia of type 1 [3]. A part from the pancreas, it is described that the lipase can be secondarily secreted to other organs, including the lungs, liver and kidneys [1] [4] [5]. The presence of LPL has been demonstrated in several other tissues, including adipose tissue, cardiac muscle, lung and kidney [6]. An abnormal expression or absence of the LPL gene in adipose tissue has been recognized as a cause of obesity. Recently, LPL has even been proposed as a new prognostic marker in chronic leukemia T cell B [7].

Okabe et al. [8] described that lung macrophages are a major source of lipases in the lungs, suggesting that lipases were involved in infectious or inflammatory processes in the lung. Jinghong Lu et al. [9] reported low production of lipoprotein lipases in the lung carcinomatosis.

If it is established that pneumocytes secrete lipase and that an inflammatory reaction with lysis occurs in the lungs, it may be postulated that serum lipase values may increase during pneumonia. So, serum lipase may be an indirect biological marker of local pulmonary inflammation [5] [6]. Pulmonary tuberculosis, which can produce various kinds of lesions, could be a model for studying the profile of lipase in pneumonia. Its evolution over several months could also help to study this profile according to the clinical stage of the disease, the biological disorders generally associated with this condition and even the impact of drug therapy on pulmonary inflammation.

So, the objective of the present study was to describe the profile of serum lipase in pulmonary tuberculosis and to identify its determinants.

\section{Patients and Methods}

A cross-sectional study was conducted in the pneumology unit of the UHK, at Lisanga medical center and 2 medical centers of save army Church. The study was conducted from July 2013 to September 2014. Patients who attended above mentioned centers because of lung tuberculosis were included. Lung tuberculosis was diagnosed according to criteria of Congolese national program for tuberculosis control. These criteria defined 4 categories of lung tuberculosis. The first category included all novel cases of lung tuberculosis with a positive bacilloscopy or extended $\mathrm{x}$-rays lesions. The second category included all patients who were treated for a second time after a successful first treatment or who re- 
ceived tuberculosis treatment after a period of interruption $>1$ month. The third category included patients who presented tuberculosis with minimal lesions (pulmonary or extra-pulmonary). The fourth category included patients who were diagnosed as lung tuberculosis while they have been previously treated for 2nd category tuberculosis. Patients were consecutively included. Their consent was obtained. Exclusion criteria were the presence of a pancreatic or a haemostasis disorder and de lack of patient consent. Controls were volunteer blood donors of the UHK blood bank.

Data were collected on a pre-established survey form. The parameters of interest were the socio-demographic characteristics of the patients (age, sex, level of education and occupation), medical history, anthropometric parameters (weight, height, body mass index), tuberculosis category and the phase of treatment.

The measurement of serum lipase and amylase was performed in the laboratory of the faculty of pharmaceutical sciences (University of Kinshasa). This measurement was made by a colorimetric enzymatic method using a semi-automatic spectrophotometer of the Humalyser Primus 2000 brand, with reagents from the Cypress Diagnostic laboratory. Dosages performed on controls were used to validate the value of the kit. Other analyses were performed in the laboratory of the UHK. The qualitative and semi-quantitative determination of C-reactive protein in the undiluted serum was performed by a latex agglutination test. The reagent used was from the Cypress Diagnostic laboratory. The haematological parameters, hemoglobin, hematocrit, red blood cells, platelets and globular constants were determined using the SYSMEX automaton. The principle of these tests was based on the variation of the impedance (DC detection) for the blood cells count and the photometry for the determination of the hemoglobin.

Table 1 is the reference values of the biological parameters sought.

The SPSS software was used for statistical analysis. Quantitative data with symmetric distribution were presented as average \pm standard deviation, and those with asymmetric distribution as median. Qualitative variables were expressed as frequency (\%). Student's t-test was used to compare the averages and the Pearson Chi-Square test to compare the proportions. The regression logistic test was used to identify the determinants of de lipasemia. The statistical significance level was 0.05 . The present study was approved by the ethics committee of the University of Kinshasa.

Table 1. Reference values of the biological parameters.

\begin{tabular}{cc}
\hline Lipase & $\leq 38 \mathrm{UI} / \mathrm{L}$ \\
\hline Amylase & $\leq 90 \mathrm{UI} / \mathrm{L}$ \\
Cholesterol & $80-200 \mathrm{mg} / \mathrm{dl}$ \\
Triglycerides & $0-150 \mathrm{mg} / \mathrm{dl}$ \\
CRP & $<6 \mathrm{mg} / \mathrm{l}$ \\
\hline
\end{tabular}




\section{Results}

Table 2 shows demographic and clinical characteristics of patients suffering from lung tuberculosis who are included in the present study.

Table 3 represents the repartition of patients according to their tuberculosis category and phase of treatment.

Figure 1 show the frequency of lipasemia. The frequency of lipasemia in the population of study was $44.5 \%$.

The average level of serum lipase was $36.6 \pm 5.0 \mathrm{IU} / \mathrm{L}$ (normal value: $<38$ U1/L) compared to $30.3 \pm 2.3 \mathrm{IU} / \mathrm{L}$ in controls. The Table 4 shows that lipase

Table 2. Demographic and clinical characteristics of studied patients.

\begin{tabular}{|c|c|}
\hline Variables & n (\%) \\
\hline \multicolumn{2}{|l|}{ Sex } \\
\hline Female & $43(33.6)$ \\
\hline Male & $85(66.4)$ \\
\hline \multicolumn{2}{|l|}{ Age (years) } \\
\hline Average & $44.4 \pm 19.3$ \\
\hline$\leq 19$ & $8(6.3)$ \\
\hline $20-29$ & $40(31.3)$ \\
\hline $30-39$ & $37(28.9)$ \\
\hline $40-49$ & $23(18.0)$ \\
\hline $50-59$ & $11(8.6)$ \\
\hline$\geq 60$ & $9(7.0)$ \\
\hline \multicolumn{2}{|l|}{ Profession } \\
\hline Jobless & $38(31.4)$ \\
\hline Civil servants & $28(21.5)$ \\
\hline Liberal & $28(23.1)$ \\
\hline Military & $14(11.6)$ \\
\hline Student & $12(9.9)$ \\
\hline Business men & $3(2.5)$ \\
\hline BMI $\left(\mathrm{Kg} / \mathrm{m}^{2}\right)$ & $20.16 \pm 5.14$ \\
\hline
\end{tabular}

Table 3. Distribution of tuberculosis patients according to the treatment phase $(n=128)$.

\begin{tabular}{ccccc}
\hline Categories & $\begin{array}{c}\text { All } \\
\mathbf{n}(\%)\end{array}$ & $\begin{array}{c}\text { Phase 1 } \\
\mathbf{n}(\%)\end{array}$ & $\begin{array}{c}\text { Phase 2 } \\
\mathbf{n}(\%)\end{array}$ & $\mathbf{p}$ \\
\hline Category I & $68(53.1)$ & $42(61.8)$ & $26(38.2)$ & 0.15 \\
Category II & $28(21.9)$ & $13(46.4)$ & $15(53.6)$ & \\
Category IV & $32(25)$ & $13(40.6)$ & $19(59.4)$ & \\
Total & 128 & $68(53.1)$ & $60(46.9)$ & \\
\hline
\end{tabular}




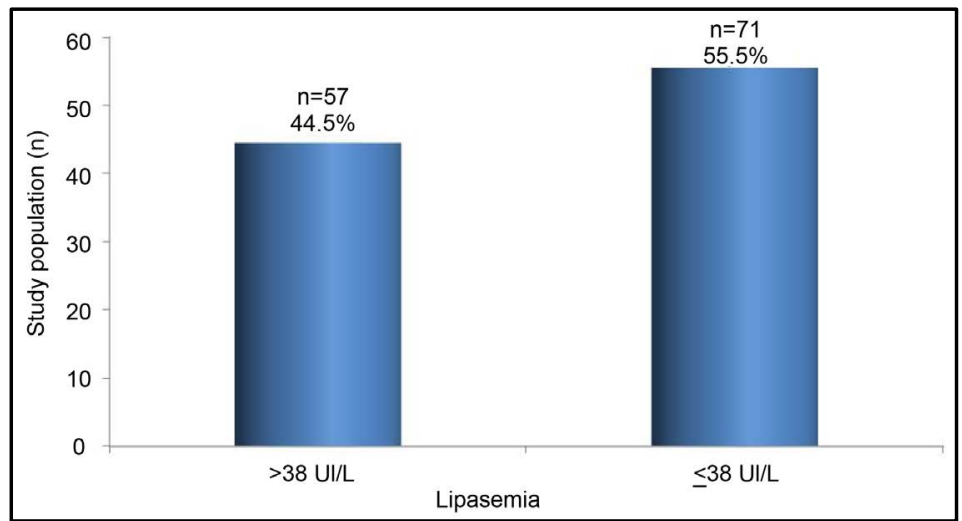

Figure 1. Frequency of lipasemia in the population of study.

Table 4. Distribution of patients regarding the level of serum lipase and Amylase ( $\mathrm{n}=$ 128).

\begin{tabular}{ccccc}
\hline & \multicolumn{2}{c}{ Lipases } & \multicolumn{2}{c}{ Amylase } \\
\hline Value & $\mathrm{n}$ & $\%$ & $\mathrm{n}$ & $\%$ \\
Normal & 71 & 55.5 & 128 & 100.0 \\
Raised & 57 & 44.5 & 0 & 0.0 \\
\hline
\end{tabular}

Normal serum lipases level: $\leq 38 \mathrm{IU} / \mathrm{L}$; Normal serum amylase level: $\leq 90 \mathrm{IU} / \mathrm{L}$.

was elevated in $44.5 \%$ of tuberculosis patients, whereas amylase was normal in all patients.

Table 5 summarizes the distribution of patients according to CRP and serum lipase level.

It can be seen that there were $14 \%$ of tuberculosis patients had high lipase levels with positive concomitant CRP.

Table 6 shows the profile of the different blood cell parameters as a function of lipasemia.

This table suggests an association between serum lipase values and white blood cell count $(\mathrm{p}=0.045)$ of platelets $(\mathrm{p}=0.028)$ and hematocrit $(\mathrm{p}=0.004)$.

The Figures 2(a)-(d) shows heterogenous situation concerning the association between lipids levels and lipasemia. Median values of serum triglycerides and cholesterol levels are higher in patients with normal lipasemia than in those with high lipasemia. There is no difference between the 2 groups of patients concerning levels of LDL-c and HDL-c.

The Table 7 shows that, in univariate analysis, high values of hematocrit, total lipids, triglycerides and cholesterol were the predictors of hyperlipasemia. But in multivariate analysis the association persisted only for total lipids and hematocrit that emerged as the main independent predictors of increased lipase. The risk of hyperlipasemia was 5-fold (ORa: 4.7) for high $\mathrm{Ht}$ and 3-fold (ORa 3.0) for high total lipids. In contrast, cholesterol, triglycerides and the tuberculosis category had a negative $(\beta)$ regression coefficients. They would therefore reduce the risk of hyperlipasemia. 
Table 5. Distribution of patients according to CRP and serum lipase level.

\begin{tabular}{ccccc}
\hline \multirow{2}{*}{ CRP } & \multicolumn{4}{c}{ Serum lipase } \\
\cline { 2 - 5 } & All patients n (\%) & $\leq 38 \mathrm{n}(\%)$ & $>38 \mathrm{n}(\%)$ & $\mathrm{P}$ \\
\hline Negative & $97(75.8$ & $48(67.6)$ & $49(86)$ & $<0.0001$ \\
Positive & $31(24.2)$ & $23(32.4)$ & $8(14)$ & \\
\hline
\end{tabular}

CRP: c-reactive protein (c-reactive protein).

Table 6. Profile of the haemogram and serum lipase level in tuberculosis patients $(\mathrm{n}=$ 128).

\begin{tabular}{|c|c|c|c|c|}
\hline Parameters & $\begin{array}{c}\text { All } \\
\text { n (\%) }\end{array}$ & $\begin{array}{c}\leq 38(\mathrm{n}=71) \\
\mathrm{n}(\%)\end{array}$ & $\begin{array}{c}>38(\mathrm{n}=57) \\
\mathrm{n}(\%)\end{array}$ & $\mathrm{p}$ \\
\hline \multicolumn{5}{|l|}{$\mathrm{WBC}(/ \mu \mathrm{L})$} \\
\hline Normal (3.700 - 9.900) & $75(58.6)$ & $50(70.4)$ & $25(47.4)$ & 0.045 \\
\hline Impaired $(<3.700)$ & $50(31.1)$ & $20(28.2)$ & $30(50.9)$ & \\
\hline Raised $(\geq 10,000)$ & $3(2.3)$ & $1(1.4)$ & $2(1.8)$ & \\
\hline \multicolumn{5}{|l|}{ Hemoglobin (g/dl) } \\
\hline Normal (10.5 - 18) & $84(64.6)$ & $57(80.3)$ & $27(47.4)$ & 0.215 \\
\hline Low $(<10.5)$ & $44(34.4)$ & $14(19.7)$ & $30(52.6)$ & \\
\hline \multicolumn{5}{|l|}{ Hematocrit (\%) } \\
\hline Normal (32 - 52) & $84(64.6)$ & $51(38.0)$ & $33(57.9)$ & 0.04 \\
\hline Low $(<32)$ & $44(34.4)$ & $20(62.0)$ & $24(42.1)$ & \\
\hline \multicolumn{5}{|l|}{ Platelets $(/ \mu \mathrm{L})$} \\
\hline Normal $(150,000-400,000)$ & $109(85.2)$ & $64(90)$ & $45(79.0)$ & 0.028 \\
\hline Low $(<150,000)$ & $10(7.8)$ & $2(3.0)$ & $8(14.0)$ & \\
\hline Raised $(>400,000)$ & $9(7.0)$ & $5(7.0)$ & $4(7.0)$ & \\
\hline
\end{tabular}

\section{Discussion}

The objective of the present study was to determine the profile of serum lipase in patients who suffered from pulmonary tuberculosis. High serum lipase levels were found in $44.5 \%$ of tuberculosis patients. The fact that the concomitant amylasemia was normal in all patients suggests that the high serum lipase level was not due to pancreatitis. While it is true that most of the lipase found in the serum is produced in the pancreas, it is also true that it is secondarily secreted by the lungs, tongue, cells of the gastric mucosa and those of the intestinal mucosa. We know that the elevation of serum lipase level during pancreatitis is due to the lyse of pancreatic cells [10] [11]. So, it may be postulated that inflammatory lesions of the lung parenchyma may also lead to a high serum lipase level.

An experimental study conducted by Querfeld et al. [12] reported an elevation of serum lipoprotein lipase produced by human monocytes-macrophages in the presence of pro-inflammatory cytokines. Okabe et al., in animal models, observed that pulmonary macrophages were an important source of lipoprotein 


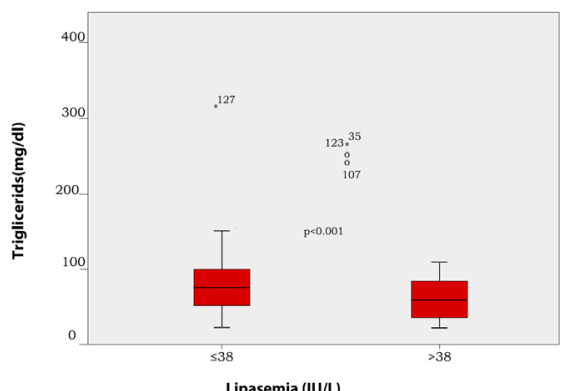

(a)

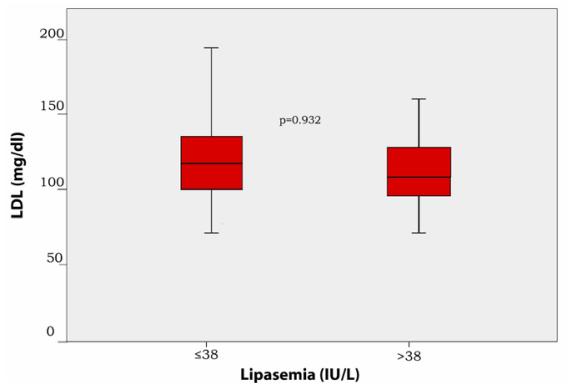

(c)

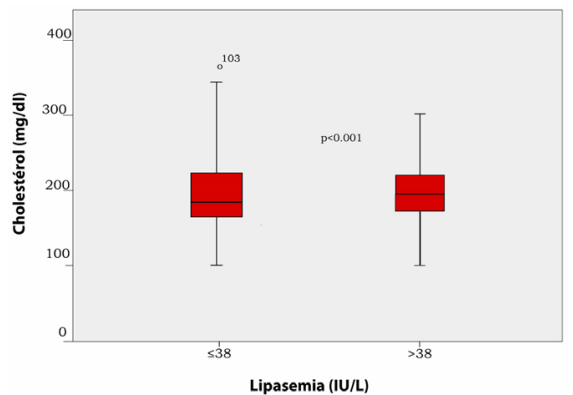

(b)

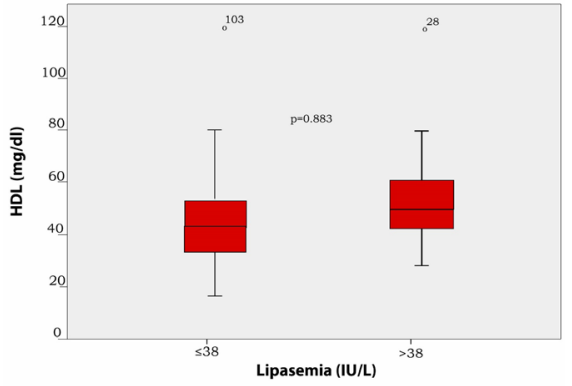

(d)

Figure 2. (a) Triglyceridemia and lipasemia in lung tuberculosis patients; (b) Association between cholesterolemia and lipasemia in lung tuberculosis patients; (c) LDL cholesterol and lipasemia in lung tuberculosis patients; (d) HDL cholesterol and lipasemia in lung tuberculosis patients.

Table 7. Predictors of increased serum lipase in lung tuberculosis patients.

\begin{tabular}{ccccc}
\hline Variable & $\beta$ & $p$ & ORa & IC95\% \\
\hline WBC high Yes vs no & -0.296 & 0.839 & 0.7 & $0.043-2.936$ \\
Ht high Yes vs no & 1.557 & $\mathbf{0 . 0 1 4}$ & 4.7 & $1.368-6.468$ \\
Platelet high Yes vs no & 0.797 & 0.098 & 2.2 & $0.863-5.706$ \\
Catégory IV Yes vs no & 0.174 & $\mathbf{0 . 0 2 8}$ & $\mathbf{3 . 5 2}$ & $\mathbf{1 . 1 1 - 6 . 3 6 1}$ \\
TBC TPM high Yes vs no & -1.903 & 0.230 & 0.15 & $0.007-8.33$ \\
Profession. Military vs no & 2.17 & $\mathbf{0 . 0 3 9}$ & $\mathbf{8 . 8}$ & $\mathbf{1 . 1 1}-\mathbf{6 9 . 1 6}$ \\
PAD* & 0.118 & 0.171 & 1.13 & $0.95-1.333$ \\
FC* & 0.128 & 0.145 & 1.13 & $0.959-1.334$ \\
Total fat high Yes vs no & 0.004 & $\mathbf{0 . 0 0 3}$ & $\mathbf{3 . 0}$ & $\mathbf{1 . 0 1 - 6 . 0 0 1}$ \\
Hypertriglyceride Yes vs no & 0.011 & $\mathbf{0 . 0 2 5}$ & $\mathbf{3 . 9 9}$ & $\mathbf{1 . 3 6 - 6 . 9 7}$ \\
Hypercholesterol Yes vs no & 0.009 & $\mathbf{0 . 0 1 8}$ & $\mathbf{2 . 9 8}$ & $\mathbf{1 . 9 8}-\mathbf{5 . 0 4}$ \\
\hline
\end{tabular}

lipase. The BK itself increased its lipase production. And this lipase induces the production of antibodies used clinically as biomarkers of active tuberculosis [13]. Inflammation of the pulmonary parenchyma is therefore involved in the hyperlipasemia described in some of the tuberculosis patients included in this study. 
However, it should be noted that the baseline values for lipaemia in the Congolese population are lacking, although the present study used a control population to validate the value of the kit. There is, moreover, the difficulty of evaluating the proportion of pulmonary secretion in the serum lipase concentration. For example, it may be thought that if lipase activity is minimal, its impact on lipase may also be minimal. It is thus understood the need to confirm these results in a context where the reference values have been determined and on a wider sample. An experimental study would have the advantage of more rationally dismantling the correlation between lung inflammation and lipase; At the same time that it could identify the factors involved. The big question in all cases is why this hyperlipasemia was observed in some (44.5\% in this study) and not in others, since all suffered from tuberculosis. High CRP was observed in only $24 \%$ of tuberculosis patients. Of those with hyperlipasemia, only $14 \%$ had a high CPR. These results are in agreement with those of Drain et al. reported that CRP is less sensitive and less specific test than Ultrasensitive CRP [14]. However, the fact that only $14 \%$ of patients with hyperlipasemia showed a concomitant increase in CRP could be explained by the fact that these patients were already on anti-tuberculosis treatment at different stages.

A study on a larger sample is desirable in order to obtain a better opinion on the subject.

The interest shown in the hemogram profile of tuberculosis patients in this study is based on the fact that abnormalities such as anemia, thrombocytopenia, leukocytosis or even leucopenia may be associated with inflammatory pathologies. In this study the mean values of the parameters of the hemogram were certainly normal, but anomalies of different figurative elements of the blood were encountered in varying proportions.

It is interesting to note that the incidence of anemia and thrombocytopenia was higher in patients with high lipase than in others. Anemia in tuberculosis is a very well-known problem [15]. The fact that it is more common in patients with hyperlipasemia may suggest that inflammation is their common substratum, although it should not be overlooked that other factors Contribute to anemia in tuberculosis (malnutrition, adrenal insufficiency, etc.).

Hematocrit and total lipid levels emerged as independent predictors of hyperlipasemia in the tuberculosis patients included in the study. The association between hematocrit and lipasemia probably proceeds in the manner described above in relation to anemia. On the other hand, the implication of the total lipids in the hyperlipasemia does not seem to have a univocal explanation. The same applies to cholesterol, triglycerides and the tuberculosis category, which would reduce the risk of hyperlipasemia. Once again, a study on a larger sample or animal model could provide a little more lighting.

\section{Conclusion}

An increase in serum lipase values is encountered in varying proportions in pa- 
tients suffering from pulmonary tuberculosis. It would be the witness of the inflammation of the lung parenchyma.

\section{References}

[1] Tietz, N.W. and Shuey, D.F. (1993) Lipase in Serum-The Clisive Enzyme: An Overview. Clinical Chemistry, 38, 1000-1010.

[2] Destain, J. and Fickers, P. (2007) Lipases Are Typical Hydrolases: Principal Characteristics and Applications. Université de Liège, Centre Wallon de Biologie industrielle, Service de Technologie Microbienne.

[3] Meyer, J.H. (1989) Pancreatic Physiology. In: Sleisenger, M.H. and Fordtran, J.S., Eds., Gastrointestinal Diseases: Pathology Diagnosis, Management, 4th Edition, W.B. Saunders, Philadelphia, 1777-1787.

[4] Stem, E.A. and Myers, G.L. (1996) Lipids, Apolipoproteins, and Lipoproteins. In: Tietz, Ed., Fundamental Clinical Chemistry, 4th Edition, W.B. Saunders Company, Philadelphia, 375-401.

[5] Moss, D.W. and Henderson, A.R. (1994) Enzymes. In: Tietz, Ed., Textbook of Clinical Chemistry, 2nd Edition, W.B Saunders Company, Philadelphia, 735-896.

[6] Irvine, J.R. and Ramji, S.A. (2002) Lipoprotein Lipase: Structure, Function, Regulation and Role in Disease. Journal of Molecular Medicine, 12, 753-769.

[7] Heintel, D., Kienle, D., Schehata, M., et al. (2005) High Expression of Lipoprotein Lipase in Poor Risk Bcell Chronic Lymphocyte Leukemia. Journal of Molecular Medicine, 19, 1216-1223.

[8] Okabe, T., Yorifuji, H., Murase, T. and Takaku, F. (1984) Pulmonary Macrophage: A Major Source of Lipoprotein Lipase in the Lung. Biochemical and Biophysical Research Communications, 125, 273-278. https://doi.org/10.1016/S0006-291X(84)80364-2

[9] Lu, J., Chaoneng, J.L., Yu, W., Xu, Z. and Huang, S. (2008) Expression of Lipoprotein Lipase Associated with Lung Carcinoma Tissue. Molecular Biology Reports, 35, 59-63. https://doi.org/10.1007/s11033-006-9053-3

[10] Greenberger, N.J. and Toskes, P.P. (2002) Pancréatites aigues et chroniques. In: Harrison, Ed., Principes de médecine interne, 15ème édition, Médecine-Sciences Flammarion, 1792-1804.

[11] Todd, K.B. and Désirée, E.M. (1999) Acute Necrotizing Pancreatitis. The New England Journal of Medicine, 340, 1412-1414. https://doi.org/10.1056/NEJM199905063401807

[12] Querfeld, L., Ong, J.M., Prehn, J., Crty, J., Saffari, B., Jordan, S.C. and Kern, P.A. (1990) Effects of Cytokines on the Production of Lipoprotein Lipase in Cultured Human Macrophages. The Journal of Lipid Research, 31, 1379-1386.

[13] Brust, B., Lecoufle, M., Tuaillon, E., Dedieu, L., Canaan, S., Valuerde, V. and Kremer, L. (2011) Mycobacterium Tuberculosis Lipolytic Enzyme as Potential Biomarkers for the Diagnosis of Active Tuberculosis. PLoS One, 6, 25078. https://doi.org/10.1371/journal.pone.0025078

[14] Drain, P.K., Mayeza, L., Bartman, P., Hurtado, R., Moodley, P., Varghese, S., Maartens, G., Alvarez, G.G. and Wilson, D. (2014) Diagnostic Accuracy and Clinical Role of Rapid C-Reactive Protein Testing in HIV-Infected Individuals with Presumed Tuberculosis in South Africa. The International Journal of Tuberculosis and Lung Disease, 18, 20-26. https://doi.org/10.5588/ijtld.13.0519 
[15] Lee, S.W., Rang, Y.A., Yoon, Y.S., Um, S.W., Lee, S.M., Yoo, C.G., Kim, Y.W., Han, S.K., Shim, Y.S. and YIM, J.J. (2006) The Prevalence and Evolution of Anemia Associated with Tuberculosis. Journal of Korean Medical Science, 21, 1028-3225. https://doi.org/10.3346/jkms.2006.21.6.1028 